\title{
ENTRE RENASCENTISTAS E FORDISTAS NA PÓS-GRADUAÇÃO: A EVOLUÇÃO DA ÁREA DO DIREITO ENTRE 2018-2021 E A REDUÇÃO DO PRODUTIVISMO ACADÊMICO NA FICHA DE AVALIAÇÃO
}

Otavio Luiz Rodrigues Jr. ${ }^{1}$

Introdução

Em novembro de 2017, quando ainda postulava a indicação da comunidade acadêmica da pós-graduação em Direito para a Coordenação de Área da CAPES Coordenação de Aperfeiçoamento de Pessoal de Nível Superior, escrevi duas colunas publicadas em revista eletrônica sobre a crise do modelo de pós-graduação e quais medidas para uma correção de rumos. ${ }^{2}$ Passados quase quatro anos e aproximando-me do fim de meu mandato na Coordenação de Área do Direito, que ocorrerá no primeiro semestre de 2022, retomo as reflexões apresentadas naquele momento e confronto-as com as transformações ocorridas na regulação da pós-graduação em Direito durante minha gestão no âmbito de um tópico central: o produtivismo acadêmico. Em certa medida, era essa a grande fonte de contestação do modelo em 2017 e nos anos subsequentes.

$\mathrm{O}$ objeto deste artigo, que se vale da estrutura das duas publicações de 2017, consiste $(i)$ na análise de dois modelos da pós-graduação em Direito, os quais poderiam ser também identificados nas Humanidades e, em certa medida, em algumas das áreas de Ciências Exatas e de Ciências da Vida: o renascentista e o fordista. Expressões essas que utilizei de modo inédito (ao menos para o Direito) em 2017 e que têm sido utilizadas em alguns artigos sobre o tema, concedendo-me os créditos por essa terminologia ${ }^{3}$ ou ignorando minha contribuição. Em uma segunda parte, $(i i)$ examinarei

1 Professor Associado de Direito Civil da Faculdade de Direito do Largo de São Francisco - Universidade de São Paulo. Coordenador da Área do Direito na CAPES (2018-2022). Conselheiro do Conselho Superior da CAPES (2019-2020 e 2021-2023).

2 RODRIGUES JR, Otavio Luiz. O modelo de pós-graduação: o dilema da qualidade e da produção. Revista Consultor Jurídico - Conjur. São Paulo: Coluna Direito Comparado, 22 de novembro de 2017. Disponível em: https://www.conjur.com.br/2017-nov-22/direito-comparado-modelo-pos-graduacao-dilema-qualidadeproducao. Acesso em: 5 maio 2021; RODRIGUES JR., Otavio Luiz. Qualidade de periódicos e controle da pós-graduação em Direito. Revista Consultor Jurídico - Conjur. São Paulo: Coluna Direito Comparado, 22 de novembro de 2017. Disponível em: https://www.conjur.com.br/2017-nov-29/direito-comparadoqualidade-periodicos-controle-pos-graduacao-direito. Acesso em: 5 maio 2021.

3 "Na percepção do atual presidente da área do Direito, inclusive, já estaria havendo uma 'vitória dos fordistas sobre os renascentistas', levando-o a lamentar, pois: 'Literatura de má qualidade, conceitos ruins ou mal-empregados, textos fast-food e outros desvios da escrita jurídica de nosso tempo são pragas cada vez mais incontroláveis (RODRIGUES JUNIOR, 2018)'”. (BEDÊ, Fayga Silveira; ALMEIDA, Marina Nogueira de; MAGALHÃES, Lincoln Mattos; OLIVEIRA, José Wendel Silva de. Autores, coautores e outros personagens: os dilemas éticos da atribuição de autoria na pesquisa jurídica - ou como chegar inteiro ao final da partida. Revista Culturas Jurídicas, v. 6, n. 15, set./dez., 2019. p. 21). 
a aplicação desses modelos na produção de periódicos e de livros. Na terceira e última parte (iii), demonstrarei a alteração radical do modelo de avaliação da Área do Direito no que se refere a essa mesma produção, a partir da Ficha de Avaliação do Direito de 2020. O peso específico da produção bibliográfica (livros e periódicos) caiu de $33 \%$ da Ficha de Avaliação anterior para 6\% do total da Ficha de 2020.

\section{Ford versus Da Vinci}

O jornal espanhol El País, em sua edição de 18 de novembro de 2017, publicou notícia com o título "Educação endurece os critérios para ser professor e catedrático universitário". ${ }^{4}$ No Reino de Espanha, o equivalente brasileiro a professor titular é o catedrático, enquanto o cargo de "professor titular" espanhol corresponde ao de "professor associado" no Brasil. Em que consistiu esse endurecimento de critérios? De acordo com a reportagem, o candidato ao cargo de catedrático nas Faculdades de Direito deverá comprovar a publicação de quatro monografias, 15 capítulos de livros e 15 artigos. Essa é, digamos, a "barreira de entrada" para concorrer à cátedra. Em outras áreas, o rigor também aumentou consideravelmente: em Matemática, são necessárias 35 publicações em revistas reconhecidas internacionalmente, ao passo que, em Física ou Química, o interessado deve comprovar a publicação de 50 artigos em periódicos indexados. O que esses números querem dizer?

Parafraseando o livro de H.G. Wells, de 1897, A Guerra dos Mundos, que narra a invasão da terra por marcianos, a universidade passou (e ainda passa) por uma guerra de (concepções) de mundo(s). Os fordistas, ${ }^{5}$ em uma analogia com o modelo de linhas de produção inaugurado por Henry Ford na fábrica de automóveis que leva seu nome, e os renascentistas, uma figuração para qualificar os que trabalham artesanalmente em busca de seu opus magum, como Leonardo da Vinci e tantos outros artistas do período histórico conhecimento como Renascimento. ${ }^{6}$

4 ÁlVAREZ, Pilar. Educación endurece los criterios para ser profesor y catedrático universitario. El Pais, 18. Nov. 2017. Disponível em: https://elpais.com/politica/2017/11/16/actualidad/1510853361_401632. html. Acesso em: 20 nov. 2017.

5 A expressão "fordismo" é canônica para as Ciências Sociais. Sua principal referência no Brasil é o capítulo de Antonio Gramsci intitulado "Americanismo e fordismo", publicado no volume 4 da coletânea: GRAMSCI, Antonio. Cadernos do cárcere. Edição de Carlos Nelson Coutinho, Marco Aurélio Nogueira e Luiz Sérgio Henriques. Tradução de Carlos Nelson Coutinho. Rio de Janeiro: Civilização Brasileira, 2000. v.4. Associa-se a uma rotina de trabalho, de caráter repetitivo e intensivo, orientado à produção em massa de bens de consumo. O modelo de linha de produção automobilística, que revolucionou essa indústria nos Estados Unidos, no início do século XX, foi uma criação de Henry Ford, fundador da empresa que leva seu nome. Daí a expressão "fordismo". Para fins deste trabalho, o "fordismo" corresponde à organização de meios e de esforços no ambiente acadêmico para a produção massiva de textos de caráter científico ou técnico, de modo alcançar bons resultados nos sistemas de avaliação da pós-graduação.

6 A Renascença é um período histórico usualmente circunscrito a meados do século XIV e fins do século 
Observando a pós-graduação, ao menos até muito recentemente, é possível afirmar de maneira peremptória que o fordismo venceu. É considerável o número de artigos publicados na última década sobre o impacto negativo do produtivismo na transformação da natureza e da função da pós-graduação no país. Em alguns desses textos, reconhecese que "a luta por espaços de poder e por recursos precede a política produtivista". $\mathrm{E}$ identificam-se fenômenos como (a) a superficialização da pesquisa; (b) "a perda da noção de autoria e coautoria", por meio de "conluios para publicação, inclusão de autores que sequer leram o trabalho visando à futura reciprocidade, apropriação de ideias de colegas e alunos, e a costumaz inclusão do nome do orientador em qualquer trabalho desenvolvido pelo aluno", tudo isso aceito com naturalidade ou mesmo estimulado por programas de pós-graduação para se atender às exigências formais da avaliação; (c) a perpetuação do produtivismo intergeracional, como método de ascensão em posições acadêmicas na universidade. ${ }^{8}$ Essas críticas não chegaram ao ponto de se negar "necessidade de considerar a produção científica na avaliação da pós-graduação", mas a de se rever os critérios dessa mesma avaliação, dado que sua condução acrítica "levaria a uma escalada da produção, processo que comumente é denominado de "produtivismo". 9

\section{Crônica de uma ruína anunciada}

O produtivismo, associado a um modelo fordista, não é recente. Ao menos no âmbito da universidade do século XX. O abandono do modelo renascentista de pós-graduação (não apenas em Direito) remonta ao câmbio ocorrido na organização burocrática dos controles acadêmicos no século passado. A despeito de ser consenso de que essa mudança ocorreu em diferentes velocidades, é possível datar o início desse processo no período que se seguiu à Primeira Guerra Mundial. É igualmente admissível localizá-lo geograficamente: o Reino Unido da Grã-Bretanha e Irlanda do Norte.

O historiador britânico Paul Johnson narra um episódio que simboliza (e sintetiza) essa mudança: embora estudasse em Cambridge, Ludwig Joseph Johann Wittgenstein (1889-1951) alistou-se como voluntário no Exército Real e Imperial

\footnotetext{
XVI, marcado por profundas transformações na sociedade, na economia e nas artes da Idade Média, com origem nas cidades-estado italianas, mas que se disseminou por toda a Europa. É metaforicamente associado neste texto a um tipo de produção acadêmica de caráter artesanal, elegante e inovador, com tempo de elaboração mais longo e maior ênfase na reflexão do que na escrita.

7 KUHLMANN JR., Moysés. Produtivismo acadêmico, publicação em periódicos e qualidade das pesquisas. Cadernos de Pesquisa, v. 45, n. 158 p. 838-855, out./dez. 2015.

8 GODOI, Christiane Kleinübing; XAVIER, Wlamir Gonçalves. O produtivismo e suas anomalias. Cadernos EBAPE.BR, v. 10, $\mathrm{n}^{\mathrm{o}}$ 2, opinião 1, jun. 2012.

9 AMAMOTO, Oswaldo H.; TOURINHO, Emmanuel Z.; BASTOS, Antônio V. B.; MENANDRO, P. R. M. Produção científica e "produtivismo": há alguma luz no final do túnel? Revista Brasileira de PósGraduação, v. 9, n. 18, 31 dez. 2012.
} 
(da Áustria-Hungria, sua terra natal) após a declaração de guerra em 1914. Por seu desempenho heroico em combate na sanguinária frente russa, Wittgenstein foi condecorado pelo imperador. Em plena guerra, ele concluiu seu opus magnum, o Tractatus LogicoPhilosophicus, livro que revolucionaria o pensamento filosófico e científico no século XX.

Com a derrota e o fim político da Áustria-Hungria, Wittgenstein tentou se adaptar à vida civil, o que se deu com enormes dificuldades em razão dos traumas de guerra. Ele terminou por voltar a Cambridge no ano de 1929. Segundo a narrativa de Paul Johnson, preocupado com a sobrevivência de Wittgenstein e com seu futuro acadêmico em razão das novas regras para admissão de docentes nas universidades britânicas, Bertrand Russell organiza uma "defesa de tese doutoral" para Wittgenstein. A tese? Muito simples: Tractatus Logico-Philosophicus. A banca, na verdade, consistiu em uma ágape intelectual entre examinadores e o "candidato". O renascentista Wittgenstein adaptava-se aos métodos fordistas graças ao engenho e à astúcia de Russel. Com o grau de doutor, Wittgenstein foi designado como fellow do Trinity College, na Universidade de Cambridge, recebendo uma bolsa a título de remuneração. Em 1939, outro benfeitor de Wittgenstein, Georg Eduard Moore, que esteve em sua banca de doutorado, aposenta-se antecipadamente. Tudo fazia parte de uma maquinação de Russell: a vaga foi preenchida por Wittgenstein em um concurso cujo resultado todos sabiam qual seria.

A história, que é verdadeira, revela as preocupações de Russell com a possibilidade de Cambridge perder um dos grandes gênios do século XX em razão da burocracia acadêmica que se instalara no Reino Unido dos anos 1930.

Com o segundo pós-guerra, os controles burocráticos aumentaram consideravelmente em todo o mundo. Reformas do ensino superior ocorreram nos anos 1960 e 1970, inclusive no Brasil, com o objetivo declarado de tornar o acesso universal (o que não significa gratuito). As revoltas estudantis de 1968, especialmente na França, na Itália e na Alemanha, foram um reflexo da luta por essas mudanças (ou dos efeitos mal calculados desses câmbios). O regime militar, no final dos anos 1960 e início dos anos 1970, instituiu o atual modelo de pós-graduação brasileiro e extinguiu o sistema de cátedras, que foi substituído pelo sistema de departamentos. Como os Acordos MECUSAID, a partir de 1965, que consistiram em convênios de cooperação entre os Estados Unidos e o Brasil na área educacional, "configurou-se, a partir daí, a orientação que estou chamando de concepção produtivista de educação. Essa concepção adquiriu força impositiva ao ser incorporada à legislação do ensino no período militar, na forma dos princípios da racionalidade, eficiência e produtividade, com os corolários do 'máximo resultado com o mínimo dispêndio' e "não duplicação de meios para fins idênticos"” Sendo certo que "o marco iniciador dessa nova fase é o ano de 1969, quando entrou em vigor a Lei da Reforma Universitária (Lei n. 5.540, de 28 de novembro de 1968), regulamentada pelo Decreto n. 464, de 11 de fevereiro de 1969, mesma data em que foi 
aprovado o Parecer CFE n. 77/69, que regulamentou a implantação da pós-graduação". ${ }^{10}$ Esse processo perdurou e ampliou-se mesmo após a redemocratização: "Esse legado do regime militar consubstanciou-se na institucionalização da visão produtivista de educação. Esta resistiu às críticas de que foi alvo nos anos de 1980 e mantém-se como hegemônica, tendo orientado a elaboração da nova LDB, promulgada em 1996, e o Plano Nacional de Educação, aprovado em 2001". ${ }^{11}$

Até então, o fordismo não havia lançado suas bases em um campo: a produção intelectual dos docentes. Embora a publicação de livros e artigos tivesse crescido exponencialmente, não havia um sistema de indexação e de controles quantitativos tão rígido. O publish or perish (publique ou pereça) não se havia instalado com todos os seus requintes.

\section{Publicar e perecer}

A grande virada ocorrerá na década de 1980, graças a Ronald Reagan (presidente dos Estados Unidos) e Margareth Thatcher (primeira-ministra do Reino Unido da Grã-Bretanha e Irlanda do Norte). Nos Estados Unidos, a administração Reagan incentivou a competição entre as universidades, seja como instrumento necessário à vitória na Guerra Fria contra a União Soviética, seja como uma estratégia de combate aos acadêmicos left-liberals (termo equivalente a acadêmicos simpáticos a algumas ideias de esquerda), que passaram a dominar as grandes universidades americanas após os anos 1960. No Reino Unido, com a grave crise econômica e orçamentária dos anos 1970, o thatcherismo chegou às universidades com a ordem: financiem-se, concorram e tornemse atraentes ao setor produtivo.

Nos Estados Unidos, o novo modelo não foi tão problemático, pois a lógica da maior parte das universidades foi do autofinanciamento e das doações privadas. No Reino Unido, sua implantação deu-se em termos menos suaves. As grandes universidades adaptaram-se, ao passo em que as médias sofreram um pesado baque.

Nos dois lados do Atlântico, a gestão acadêmica tem-se distinguido cada vez mais da gestão financeira. A administração "empresarial” das grandes universidades britânicas e norte-americanas foi o grande legado da era Reagan-Thatcher, ao menos nos níveis atualmente praticados.

Participei de um restrito simpósio internacional de pesquisadores de Responsabilidade Civil Comparada na Universidade de Cambridge no ano de 2016 e

10 SAVIANI, Dermeval. O legado educacional do regime militar. Cadernos Cedes, v. 28, n. 76, p. 291-312, set./dez. 2008. p. 297.

11 SAVIANI, Dermeval. O legado educacional do regime militar. Cadernos Cedes, v. 28, n. 76, p. 291-312, set./dez. 2008. p. 298. 
pude compreender melhor essa estrutura de financiamento universitário: quase tudo no campus era voltado para receber estudantes ou docentes estrangeiros e a otimizar espaços para que as instalações e os cursos da universidade fossem rentabilizados. Não é sem causa que, nos anos de 2003 e 2004, as universidades britânicas foram responsáveis por ingressos financeiros da ordem de 28 bilhões de libras esterlinas, apenas com a presença de estudantes estrangeiros. No mesmo período, a indústria automobilística faturou 20 bilhões de libras esterlinas, e o setor de serviços, o valor de 19 bilhões de libras esterlinas. Segundo dados do Governo britânico, "em 2011, a estimativa é de que o setor [educacional] tenha contribuído com 17.5 bi de libras esterlinas para a economia do país - $61 \%$ vindos da educação superior, assim como atraído $13 \%$ dos estudantes internacionais de todo o mundo, o que coloca o Reino Unido como o segundo principal destino, logo atrás dos Estados Unidos que recebeu 16.5\% dos estudantes internacionais". ${ }^{12}$ Os resultados são impressionantes: "Com 1\% da população mundial, o Reino Unido tem produzido 9\% dos papers científicos; 13\% dos trabalhos mais citados; conquistado $10 \%$ dos prêmios de pesquisa mais reconhecidos internacionalmente; em 50 anos, tem 44 vencedores de Prêmio Nobel; a produtividade de pesquisa tem sido superior a de países líderes como EUA e Japão - 16 artigos científicos para cada milhão de libras esterlinas investidas comparado com 10 artigos produzidos pelos EUA e 4 pelo Japão; e conta com várias universidades entre as melhores do mundo nos principais rankings atualmente publicados". ${ }^{13}$

Para que essa máquina funcione, é necessário um processo de retroalimentação, que envolve prestígio para atrair bons alunos e pesquisadores, os quais conseguem prêmios, patentes e bolsas, que, por sua vez, servem para aumentar o prestígio e trazer mais discentes e pesquisadores e, na sequência, mais doadores (ou financiadores). Nesse círculo virtuoso, os rankings, as distinções e os prêmios acadêmicos são fundamentais. E como ficar bem nesses indicadores? Com critérios qualitativos, é claro. Mas não apenas. São centrais os critérios quantitativos. Número de publicações indexadas, por exemplo, é um desses elementos. ${ }^{14}$

12 MESQUIATI, Luiz Fabio. A educação superior no Reino Unido: expansão e internacionalização. Revista Eletrônica de Educação, v. 8, n. 1, p. 22-42, 2014. p. 26.

13 Idem, ibidem, p. 25.

14 "No que se refere à manutenção do sistema, o HEFCE-Higher Education Funding Council for England é o principal órgão responsável pelo fomento da Educação Superior no Reino Unido e o gestor dos recursos alocados dentro do sistema. Anualmente é feita a distribuição dos recursos, em declínio como poderá ser observado nos gráficos abaixo, entre universidades e colleges. O financiamento público representa hoje menos de $40 \%$ do orçamento total das instituições e a alocação de recursos leva em consideração aspectos como acesso e inclusão; qualidade de ensino e pesquisa; integração universidades/colleges e indústria/comunidade; apoio à diversidade; eficiência na gestão dos recursos públicos; previsibilidade do financiamento público para que instituições possam se planejar e definir seus orçamentos de maneira efetiva. Os critérios para distribuição de recursos contemplam número e perfil de estudantes, cursos oferecidos e quantidade e qualidade da pesquisa. Para a avaliação da quantidade e qualidade da pesquisa, 
Uma história que me foi narrada exemplifica tal processo: uma doutoranda em uma universidade norte-americana apresentou dois artigos a seu orientador, como requisito para a obtenção do título (em muitas faculdades de exatas, a publicação de artigos substitui a elaboração de teses). O orientador considerou que os papers estavam adequados para bons periódicos e mandou que a aluna os enviasse para as revistas, o que é algo bem planejado nos Estados Unidos, envolvendo até mesmo uma janela em certos meses no ano. Poucas semanas depois, ela foi procurada pelo orientador com uma contraordem: ela deveria direcionar os artigos para periódicos com indexação mais valorizada. Isso implicaria enorme esforço da doutoranda para reelaborar os textos, que já haviam sido considerados bons. Ela se atreveu a perguntar o porquê dessa mudança. $\mathrm{O}$ orientador respondeu com franqueza: "Fui procurado pelo deão da faculdade. Ele precisa que subamos no ranking deste ano para que possamos pleitear mais bolsas para jogadores de basquetebol que vão atuar na liga americana. Com isso, teremos uma participação maior na verba de publicidade dos jogos da liga e poderemos financiar pesquisas em nossa unidade".

Esse entrelaçar de financiamento, prestígio e produção, que se tornou típico dos modelos norte-americano e britânico (não no sentido de modelo jurídico, é claro), terminou por ser exportado para o resto do mundo. E é nas pós-graduações, o locus por excelência da produção científica. Espaços para pesquisadores renascentistas ainda existem. Mas até estes são cobrados pelos controles de produção. É vulgar, nesses casos, aquelas publicações em coautoria com pesquisadores ou professores assistentes, uma prática que começa a ser criticada em alguns fóruns científicos, até mesmo em razão de denúncias de jovens pesquisadores que se julgaram preteridos em suas carreiras nas universidades e se voltam contra seus (supostos) "exploradores". ${ }^{15}$

elemento-chave na alocação dos recursos, tem-se hoje o Research Excellence Framework cujos principais critérios de avaliação são: resultados da pesquisa (originalidade, relevância e rigor) com peso 65\%; Impacto (alcance e relevância) com peso de 20\%; e Ambiente (vitalidade e sustentabilidade) representando $15 \%$ da avaliação. O objetivo principal do processo de avaliação é construir perfis de qualidade das instituições de educação superior e criar um mecanismo de estímulo a uma produção científica de caráter internacional." MESQUIATI, Luiz Fabio. A educação superior no Reino Unido: expansão e internacionalização. Revista Eletrônica de Educação, v. 8, n. 1, p. 22-42, 2014. p. 28-29.

15 "No Brasil e em várias partes do mundo, são crescentes os casos envolvendo más condutas em pesquisas científicas, tais como: manipulação, falsificação ou fabricação de dados ou de resultados, plágio, autoplágio (apresentação total ou parcial de textos já publicados pelo mesmo autor como se fossem inéditos), bem como a prática - bastante comum, diga-se de passagem - da coautoria de fachada" (REGO, Teresa Cristina. Produtivismo, pesquisa e comunicação científica: entre o veneno e o remédio. Educação e Pesquisa, v. 40, n. 2, p. 325-346, abr./jun. 2014. p. 338). 
4. O Direito nas "oficinas de florestas"

Até então preservada por sua "específica especificidade" (com o perdão pela hipérbole), a pós-graduação em Direito foi convocada para essa luta por posições nos rankings, de modo especial, a partir de meados dos anos 2000. Como em uma guerra total, até mesmo unidades não combatentes terminam por ser chamadas ao front. Há, pelo menos, duas décadas, o Direito e sua pós-graduação vêm sendo inseridos (muita vez contra sua vontade) nesse processo de controle fordista das produções em livros e periódicos. Isso é perceptível por uma mera leitura das Fichas de Avaliação do Direito no respectivo período.

Em 2004, Roberto Fragale Filho e Alexandre Veronese analisaram o desenvolvimento da pesquisa na Área do Direito. Na época, havia 52 programas de pósgraduação em Direito. Em 1981, havia 12 Mestrados e 4 doutorados. Até julho de 2004, esse número passou para 37 Mestrados e 15 Doutorados. ${ }^{16}$ Segundo os autores, "essa expansão proporcionou, necessariamente, um aumento da produção de pesquisa formal e, por via de conseqüência, de publicações, já que seus resultados são veiculados em livros e periódicos científicos". ${ }^{17}$ Essa correlação entre um número maior de programas de pós-graduação em Direito e uma ampliação da produção bibliográfica é autoevidente. Mas os autores identificaram também um número crescente de livros e artigos publicados na Área do Direito, o que já se percebia como um signo dessa tentativa de adaptação da Área a critérios de avaliação universalizados (ou em vias de universalização) no âmbito do Sistema Nacional de Pós-Graduação.

Essa "oficina de florestas", que começou a ser mapeada na década de 2000, só foi percebida mais diretamente nos programas de pós-graduação na medida em que as diretrizes de avaliação da CAPES começaram a produzir efeitos no credenciamento e no recredenciamento de docentes. Era absolutamente ordinário inexistirem regras para ingresso ou permanência nos programas. Prevalecia a discricionariedade das coordenações, a vocação dos interessados ou simplesmente o desejo de assumir mais encargos na universidade. No Direito, isso era ainda mais sensível. As primeiras regras de credenciamento e recredenciamento, ainda assim, eram muito frouxas quanto à observância de parâmetros objetivos (participação em bancas examinadoras; número de créditos oferecidos; quantidade de publicações indexadas, dentre outros).

Pode-se afirmar que prevaleceu no Direito até o início dos anos 2000, especialmente nas instituições públicas, o modelo renascentista puro. A figura dos grandes catedráticos - alguns poucos remanescentes do regime anterior à Reforma

16 FRAGALE FILHO, Roberto; VERONESE, Alexandre. A pesquisa em Direito: diagnóstico e perspectivas. Revista Brasileira de Pós-Graduação, v. 1, n. 2, p. 53-70, nov. 2004. p. 55.

17 Idem, ibidem, p. 58. 
Universitária - e dos renomados professores titulares impunha-se em detrimento das diretrizes da CAPES. O prestígio imaterial desses docentes, com décadas de publicações e enorme influência na formação do pensamento jurídico ou mesmo da jurisprudência, contava muito mais do que o controle numérico e objetivo estabelecido pelos padrões fordistas. Não é sem causa o enorme estranhamento dos mais antigos e tradicionais programas de pós-graduação em Direito ao que se pode chamar de uma "virada fordista" no início do século XX.

Passou-se de uma fase de negação desse novo modelo para uma fase de insurgência pouco eficaz. Esse processo é muito semelhante ao que ocorreu logo após a Emenda Constitucional $\mathrm{n}^{\circ} 45$, de 30 de dezembro de 2004, haver criado o Conselho Nacional de Justiça e o Conselho Nacional do Ministério Público. A reação dos tribunais foi muito semelhante e igualmente ineficaz. Os parâmetros objetivos de controle da atividade jurisdicional impuseram-se e os tribunais refratários às mudanças tiveram de se adaptar. Os juízes que não se enquadraram nesse novo modelo sofreram sanções disciplinares, o que é algo inédito na História do Poder Judiciário nacional. As discussões sobre o "fordismo judiciário" passaram a interessar estudiosos de Direito e Sociologia. ${ }^{18}$ A qualidade das sentenças, sua natureza artesanal e erudita, que eram os padrões definidores do conceito de um bom juiz, tudo isso foi posto em xeque diante de magistrados mais ágeis, familiarizados com os recursos da Tecnologia da Informação ou com técnicas de gestão judiciária. Boas sentenças deixaram de ser o parâmetro para se privilegiar os "campeões de produção".

A semelhança do que ocorreu com o controle dos órgãos do Poder Judiciário $^{19}$ e a introdução do modelo fordista na pós-graduação (em Direito) no Brasil é também perceptível na criação do "mito renascentista". Assim pode ser denominado uma espécie de mistificação quanto ao período pré-fordista, como se ele houvesse sido um "paraíso perdido" acadêmico. É certo que na fase renascentista, os grandes pesquisadores - que formaram seu prestígio e o de suas instituições por meio de uma produção sólida e

18 São exemplos dessa literatura, inclusive com o uso da terminologia "fordismo": FONTAINHA, Fernando de Castro. Informatização da vida e dos tribunais no Brasil. Revista direito GV, v. 3, n. 1, p. 57-74, jan./ jun. 2007; FONTAINHA, Fernando de Castro. A informatização do judiciário e seus empreendedores. Revista jurídica: órgão cultural da Faculdade Nacional de Direito da Universidade do Brasil, v. 1, n. 4, p. 93-115, maio 2010; MARTINS, Ana Paula Antunes; COLARES, Elisa Sardão. "Fordismo judiciário": a administração do judiciário no Brasil e os impactos nos processos de execução fiscal. In. CUNHA, Alexandre dos Santos; SILVA, Paulo Eduardo Alves (coord). Gestão e Jurisdição o caso da execução fiscal da União. Brasília: Ipea, 2013. p. 283-299; SILVA, Paulo Eduardo Alves da. Gerenciamento de processos judiciais. São Paulo: Saraiva, 2010; GONÇALVES, Gláucio Ferreira Maciel. Gerenciamento dos processos judiciais: notas sobre a experiência processual civil na Inglaterra pós-codificação. Revista da Faculdade de Direito da Universidade Federal de Minas Gerais, n. 66, p. 291-326, jan./jun. 2015.

19 Refere-se apenas ao Poder Judiciário por não se identificar semelhante impacto no Ministério Público, mesmo com a criação do Conselho Nacional do Ministério Público. As razões dessa assimetria não interessam ao estudo aqui desenvolvido e não serão exploradas. 
refletida -, favoreceram-se de um modelo acadêmico menos inclusivo, com um número muito menor de programas e sem a sobrecarga burocrática universitária (participação em comissões, controles de produtividade e transferência de atividades-meio para os docentes, como administração de notas e lançamento de faltas de discentes). Imaginar que isso seria hoje sustentável equivale a acreditar que a produção de vestuário dos anos 1950, preponderantemente feito por alfaiates e estilistas, com uso de tecidos naturais, atenderia à demanda contemporânea de uma população que cresceu a taxas de progressão geométrica nos últimos 70 anos, atendida hoje por tecidos sintéticos e produção industrial que oferece a chamada fast fashion.

A falta de controles da fase renascentista não permite igualmente identificar as deficiências na pesquisa em pós-graduação daquele período. Se é certo que o sistema foi capaz de gerar grandes nomes, seria pouco honesto intelectualmente negar a existência de docentes que não se enquadrariam em padrões elevados de qualidade acadêmica, mesmo à época. É nesse sentido que se deve também negar direito de cidade à concepção ordinariamente aceita de que existiu um "paraíso perdido" na fase renascentista. Em uma metáfora forçada, Da Vinci, Ticiano, Bosch e Caravaggio (do Direito) conviveram com um número bem maior de obscuros artesãos acadêmicos do que seus referentes dos séculos XIV-XVI.

5. Os três movimentos da década 2010 na avaliação da produção em periódicos e a “corrida armamentista" por pontos

O fordismo terminou por se consolidar e, na década de 2010, os sinais mais evidentes de seu triunfo estavam na "corrida armamentista" por pontos no sistema avaliação da CAPES, fortemente alimentada pela produção em periódicos. Identificamse aqui três interessantes movimentos:

(a) A crescente uniformização dos critérios de avaliação, cujo símbolo maior foi a introdução do "sistema brasileiro de avaliação de periódicos", o QualisCAPES, desenvolvido a partir de 2012. Os periódicos passaram a ser classificados por estratos, os quais seriam representativos da qualidade da revista e associavam-se a um número de pontos. Os estratos dividiam-se em superiores (A1, A2, B1 e B2) e inferiores (B3, B4, B5 e C). As revistas científicas eram avaliadas periodicamente (dentro dos ciclos avaliativos da CAPES) e, ao final de cada ciclo, as Comissões de Área contabilizavam a produção docente e discente dos programas, levando em conta o total de pontos do triênio (quando o ciclo era trienal) ou do quadriênio (quando o ciclo avaliativo passou a ser quadrienal).

Os critérios definidores da classificação dos periódicos eram definidos por cada Área, após uma validação formal pelo órgão competente da CAPES, a Diretoria de Avaliação - DAV. Prevaleceram na década de 2010 os (i) critérios formais, embora, 
ao menos para os estratos A1 e A2, houvesse espaço para (ii) critérios materiais. Os primeiros (i) referiam-se à observância de padrões editoriais mínimos (presença de resumo e abstract; palavras-chave e key words; rodapé com elementos pretextuais; uso de um sistema uniforme de notação bibliográfica; inserção do endereço eletrônico dos autores; pontualidade e periodicidade das edições) e de regras indutoras de revisão cega por pares, de diversificação geográfica, de internacionalização e do uso de línguas estrangeiras. Criaram-se métricas muito complexas para o cálculo da exogenia de autores e de membros do conselho editorial e do conselho de pareceristas; da presença de autores estrangeiros; e do ineditismo dos textos. Os segundos (ii) refletiam-se basicamente na inclusão em indexadores (Scielo, Scopus, Web of Science) e no fator de impacto dos periódicos.

(b) A tendência à unificação dos critérios do Qualis/Capes entre as diferentes Áreas acentuou-se no final da década de 2019. O objetivo era se chegar a um Qualis único, passível de se atribuir o mesmo estrato a qualquer periódico, independentemente da Área, utilizando-se de critérios universais. Fundamentalmente, os critérios formais eram passariam a ser considerados pressupostos e examinar-seiam apenas os critérios materiais por meio de robôs que identificariam a presença nos indexadores e o fato de impacto. Esse processo ainda não foi concluído, embora já tenha acenado com a extinção do Qualis como uma meta para o novo modelo avaliativo da década de 2020 .

(c) A prevalência da produção em periódicos em face da produção em livros foi o terceiro movimento observado na última década. O objetivo era alcançar posições mais elevadas nos rankings universitários internacionais, o que implicava aumentar a produção em periódicos, o único "ativo conversível” internacionalmente por critérios geralmente comuns aos diversos países. Evidentemente que esse movimento também se inseria em uma política de "adesão" das Humanidades aos standards das Ciências Exatas e das Ciências da Vida. Na Área do Direito, por exemplo, na avaliação quadrienal de 2017, menos de 10 livros alcançaram o estrato máximo (L4), o que dá um percentual de $0,66 \%$ da produção bibliográfica da Área.

Como em todo processo de evolução regulatória, alguns são mais ágeis na adaptação aos novos padrões de avaliação. Isso também ocorreu na Área do Direito. Programas menores e com hierarquias bem consolidadas conseguiram alterar as regras de credenciamento e recredenciamento de docentes em ordem a privilegiar o principal item da antiga Ficha de Avaliação, a produção bibliográfica. 
No Direito, até a adoção da nova Ficha de Avaliação de $2020,{ }^{20}$ o peso da produção bibliográfica correspondia a $33 \%$ do total de pontos da ficha, conforme o Documento da Área de 2013. ${ }^{21}$

Essa correlação entre produção bibliográfica e os demais itens da Ficha de Avaliação explica com muita contundência o porquê da "corrida armamentista" instalada entre os programas. Da fase de negação, chegou-se à resistência ineficaz. Mas, como último estágio, alcançou-se a fase da "corrida armamentista". De um modo quase que universal, compreendeu-se que ser mal avaliado implicaria uma série de consequências: a) sair do sistema de avaliação, por não se alcançar a nota mínima 3 para Mestrado ou 4 para Doutorado; b) perder prestígio acadêmico; c) reduzir a capacidade de atração de docentes e discentes; d) inviabilizar a consecução de cursos de Doutorado. Independentemente dessas externalidades, há duas outras que se revelaram ainda mais importantes. (i) A primeira está no acesso a programas e fontes de fomento e de financiamento à pesquisa e a programas de bolsas. A nota do programa de pós-graduação, especialmente aqueles avaliados como 5, 6 e 7, é um fator que define o acesso a tais fontes e programas, como o Programa de Excelência Acadêmica - Proex/CAPES e o Programa Institucional de Internacionalização - CAPES Print. (ii) A segunda está na internacionalização e no posicionamento em face de rankings acadêmicos e no acesso às redes internacionais de pesquisa. Ser bem avaliado pela agência estatal de cada país é uma espécie de cartão de visitas para se apresentar como um ator relevante no cenário da pós-graduação global.

Diante disso, mesmo os programas refratários a admitir o novo modelo de pós-graduação fordista tiveram de corrigir seus rumos. Mais do que tudo, criou-se uma guerra por pontos na avaliação com características muito aproximadas à corrida armamentista entre Estados Unidos e União Soviética, no auge da guerra fria dos anos 1950-1980. Como a avaliação é comparativa, só ao final do antigo triênio e hoje quadriênio é que se conhece o nível de produção de cada programa. Com isso, a única forma de tentar uma boa posição no sistema era elevar as exigências de produção para docentes e discentes a cada ano. Limites cada vez mais absurdos eram impostos. Programas mais ágeis e (paradoxalmente) mais hierarquizados conseguiam alcançar esses padrões de "excelência" com maior velocidade do que programas de perfil burocrático e com baixa capacidade de enforcement sobre seus docentes.

O bom docente era aquele que mais produzia. Pouco interessava se, para isso, eram adotadas práticas como (a) o fracionamento de teses e dissertações; (b) a produção compulsória em coautoria com discentes; (c) a busca compulsiva por periódicos

20 Disponível em: https://www.gov.br/capes/pt-br/centrais-de-conteudo/documentos/avaliacao/copy_of_ FICHA_DIREITO_2_ATUALIZADA.pdf. Acesso em: 5 maio 2021.

21 Disponível em: https://www.gov.br/capes/pt-br/centrais-de-conteudo/Direito_doc_area_e_comisso_16out. pdf. Acesso em: 20 maio 2021. 
de estratos mais elevados; (d) a explosão na criação de periódicos abertos, algo facilitado pelo desenvolvimento e popularização de programas de editoração gratuitos. Algumas dessas práticas associavam-se a ações de duvidoso padrão ético, as quais, na maior parte dos casos, eram identificadas apenas na Avaliação Quadrienal.

$\mathrm{O}$ auge do modelo fordista levou ao desenvolvimento de uma série de críticas e propostas para sua alteração.

6. Medidas adotadas para a evolução da Área do Direito no período de 2018-2021

Desde a posse na Coordenação de Área em 2018, ${ }^{22}$ com amplo apoio e colaboração das coordenações de programas de pós-graduação em Direito, deu-se início a uma série de ações institucionais para se ampliar e disseminar uma cultura de "juridicização" dos procedimentos na Área do Direito, em paralelo a um processo de desmonte do fordismo, além do povoamento de regiões desprovidas de programas de pósgraduação. Essas medidas também foram marcadas pela formalização de boas práticas de transparência, análise de impacto regulatório, consultas e audiências públicas, bem como de controle a eventuais conflitos de interesses.

Em linhas gerais, podem-se enumerar algumas dessas medidas: ${ }^{23}$

(a) Criação ou formalização de regras de impessoalidade e transparência: Por meio de documentos oficiais da Área, vedou-se a participação de profissionais de consultoria privada (para criação ou assessoramento de cursos de pós-graduação) nas comissões da Área. Além disso, os membros das comissões passaram a ser obrigados a assinar termos de confidencialidade e de conflito de interesses antes de atuarem em seus ofícios. Nas reuniões das comissões, os membros não tinham direito a voz nem a voto nas deliberações envolvendo seus próprios programas ou aqueles sediados em sua unidade da federação. Os membros saíam do recinto quando ocorriam essas deliberações. A divulgação dos resultados das avaliações passou a só ocorrer após ato oficial da CAPES, evitando-se a assimetria informacional. Como medida adicional, todas as informações repassadas aos programas só possuíam valor jurídico se transmitidas via correio eletrônico da Área.

(b) Utilização de mecanismos regulatórios como audiências públicas e consultas públicas: A apresentação de propostas de mudança no sistema de avaliação passou a se dar mediante audiências públicas, geralmente ocorridas durante os fóruns

22 Ao lado de Flaviane de Magalhães Barros Bolzan de Moraes (UFOP/PUC Minas) e Ingo Wolfgang Sarlet (PUC/RS), posteriormente com Felipe Chiarello de Souza Pinto (Universidade Presbiteriana Mackenzie).

23 Embora não todas, mas a quase totalidade dessas ações está documentada na página da CAPES. Disponível em: https://www.gov.br/capes/pt-br/acesso-a-informacao/acoes-e-programas/avaliacao/sobre-a-avaliacao/ areas-avaliacao/sobre-as-areas-de-avaliacao/colegio-de-humanidades/ciencias-sociais-aplicadas/direito. Acesso em: 30 maio 2021. 
de coordenadores de programas de pós-graduação (Salvador, São Paulo, Porto Alegre e Goiânia), e em consultas públicas, abertas à comunidade, com o recebimento de centenas de proposições para aprimorar o processo regulatório.

(c) Mudança na estrutura formal dos documentos da Área: Mesmo com os riscos de uma eventual crítica por excesso de singularidade, todos os documentos da Área passaram a adotar uma forma mais jurídica, com separação dos parágrafos por itens e subitens; uma linguagem mais objetiva e com formato normativo (e menos discursivo); e emprego de remissões internas.

(d) Alteração do documento de abertura de cursos novos (APCN): $\mathrm{O}$ documento orientador de APCNS foi totalmente reelaborado. ${ }^{24}$ Dentre suas principais inovações, estão: (i) maior clareza e especificação de exigências quantitativas e qualitativas; (ii) aumento do número mínimo de docentes para abertura de doutorado; (iii) estímulo à formulação de propostas voltadas para atender às carências nas áreas de especialização do Direito; (iv) exigências determinadas quanto a uma política de constituição e renovação de acervo de livros e periódicos; (v) ênfase e objetivação das exigências de acessibilidade física; (vi) mecanismos de contenção da precarização docente; (vii) estímulo maior à internacionalização e à busca pelo impacto social dos programas; (viii) clareza na distinção entre programas acadêmicos e profissionais.

(e) Incentivo ao povoamento das Regiões Norte, Nordeste e CentroOeste com novos programas de pós-graduação: Sem flexibilizar os critérios comuns e universais do Documento Orientador de APCN, a Área impulsionou a ampliação do número de Mestrados e Doutorados nas respectivas Regiões do país com maiores carências na pós-graduação. Em 2018, o Estado do Piauí obteve seu primeiro Mestrado em Direito, deixando de ser a última unidade federada da Região Nordeste sem um curso de pós-graduação em sentido estrito na Área do Direito. A Faculdade de Direito da Universidade Federal do Amazonas, fundada em 1909, só conseguiu a instalação de seu primeiro Mestrado em 2018. ${ }^{25}$ Outros cursos de Mestrado e Doutorado, acadêmicos e profissionais, foram autorizados no Rio Grande do Norte, em Goiás, no Distrito Federal, no Maranhão, na Bahia e no Sergipe, além da abertura de cursos no interior de Estados das Regiões Sul e Sudeste.

(f) Eliminação de redutores de nota por efeito de reprovação de discentes: Uma grave distorção no processo avaliativo era a redução de nota dos programas pelo índice de reprovação dos discentes. Provavelmente ligado ao controle da oferta

24 Disponível em: https://www.gov.br/capes/pt-br/centrais-de-conteudo/documentos/avaliacao/APCN DIREITO.pdf. Acesso em: 2 jun. 2021.

25 COELHO, Gabriela. Universidade federais do Norte e do Nordeste terão mestrado em Direito. Consultor Jurídico, 21 de dezembro de 2018. Acesso em: 20 jun. 2021. Disponível em: https://www.conjur.com. br/2018-dez-21/tres-universidades-federais-terao-mestrado-doutorado-direito. 
e da fruição de bolsas de pós-graduação, esse redutor criou - ao longo dos anos - uma política artificial de aprovação irrestrita de discentes, mesmo com dissertações ou teses abaixo de padrões esperáveis de qualidade ou com desempenho escolar medíocre. A Ficha de Avaliação do Direito de 2020 expressamente eliminou do cálculo do "índice quantitativo de formação" (item 2.5.4) o "desligamento do programa por reprovação por faltas, insuficiência de desempenho nas disciplinas ou reprovação da dissertação ou tese perante banca examinadora". Com isso tornou-se possível iniciar uma nova cultura de valorização do mérito da formação discente em preeminência sobre um índice calculado para se atender a resultados do sistema de avaliação.

(g) Reconhecimento do impacto de licenças e da saúde de discentes e docentes no "índice quantitativo de formação": Com idêntica finalidade à medida "f", excluíram-se da base de cálculo do "índice quantitativo de formação" (item 2.5.4 da Ficha de Avaliação de 2020) os seguintes eventos: licença médica de discentes (superior a 30 dias); licença-maternidade e licença-paternidade; trancamento parcial da matrícula, justificado pelas normas do curso por razões específicas, previstas em normas internas; conversão de mestrado em doutorado direto.

Uma série de situações caracterizáveis como típica injustiça histórica e de assimetria entre indivíduos, marcadamente por questões de gênero, terminou por ser superada com essas medidas. A paternidade ou a maternidade durante a pós-graduação, seja para docentes, seja para discentes, deixou de impactar o "índice quantitativo de formação" (item 2.5.4 da Ficha de Avaliação de 2020) e, com isso, de modo indireto, liberou os programas de exigir o cumprimento de metas ou de prazos em igualdade de condições com os demais integrantes do curso. De modo ainda mais explícito, a Ficha de Avaliação do Direito de 2020, na observação 4 ao item 2.4. (“Qualidade das atividades de pesquisa e da produção intelectual do corpo docente no programa"), definiu que: "Excluir-se-á, por meio de anexo específico, a produção de professoras em licençamaternidade e docentes em licença médica superior a 30 dias, que usufruíram desse direito entre 2016 e 2020, a partir do ano de início da licença até o final do quadriênio".

As estatísticas revelam o crescente comprometimento da saúde mental na pós-graduação, em particular de estudantes, com a ampliação de licenças-médicas. A Ficha de Avaliação considerou, como descrito, tais realidades ao permitir a dilatação de prazos de conclusão do curso para pessoas em licença-médica superior a 30 dias.

(h) Valorização da atividade de editoração de periódicos: Outra inovação importante contida no "Documento de Orientações quanto ao registro de resultados e produções" 26 consistiu no reconhecimento como produto técnico-tecnológico, susceptível $\begin{array}{ll}26 & \text { Disponível em: https://www.gov.br/capes/pt-br/centrais-de-conteudo/documentos/avaliacao/ } \\ \text { ORIENTACOES_DIREITO_ATUALIZADA.pdf. Acesso em: } 20 \text { jun. } 2021 .\end{array}$ 
de pontuação autônoma, da seguinte atividade: "Produto de editoração (organização de livro, coletânea, dicionário e enciclopédia; participação como editor ou integrante do corpo editorial de revista científica ou de anais de eventos científicos)". Editores e membros de conselhos editoriais passaram a figurar autonomamente como agentes relevantes no processo avaliativo.

7. A redução do produtivismo acadêmico na Ficha de Avaliação da Área do Direito de 2020

A principal transformação ocorrida na Área de Direito, para além das alterações descritas na seção 6 , está no peso atribuído à produção bibliográfica. Como descrito na Introdução, o peso específico da produção bibliográfica (livros e periódicos) caiu de 33\% da Ficha de Avaliação anterior para 6\% do total da Ficha de Avaliação do Direito de 2020.

Essa é uma mudança revolucionária em termos de interrupção do processo aqui denominado de "corrida armamentista" entre os programas para se alcançar um número crescente de pontos no que foi o item mais relevante da Ficha de Avaliação. Esse é um câmbio de enormes proporções no modo como os programas se organizam para a Avaliação Quadrienal e na maneira como a CAPES passa a classificá-los.

$\mathrm{O}$ discurso de ataque ao produtivismo, quase sempre vinculado a uma crítica institucional à CAPES, ao sistema de avaliação e às Áreas, especialmente na última década, converteu-se em um mantra em diversos fóruns acadêmicos. A mudança, por tanto tempo desejada, finalmente ocorreu e está positivada na Ficha de Avaliação da Área. Seu impacto no planejamento estratégico, nos sistemas de autoavaliação, nas regras de credenciamento e recredenciamento dos programas de pós-graduação ainda não se fez sentir de modo generalizado. Mais do que isso: na percepção do sistema de pós-graduação, em particular na representação feita por docentes e discentes a respeito de seu papel no sistema, essas mudanças ainda não se materializaram. Os esforços dos programas ainda se orientam para o produtivismo. A qualidade ou o mérito dos docentes continua a ser medido pelo número de publicações em estratos elevados. Não se muda facilmente uma cultura de avaliação comparativa fundada em controles numéricos de produção bibliográfica que já dura 20 anos. O que não é admissível, contudo, salvo por ignorância sobre o conteúdo da nova Ficha de Avaliação, a continuidade do discurso crítico à CAPES em razão do fordismo acadêmico. Na Área do Direito, esta é uma página virada.

A nova avaliação dos programas de pós-graduação em Direito estrutura-se em 3 itens: Programa, Formação e Impacto na Sociedade. 
No quesito 1 (Programa), localizam-se elementos como: (a) coerência e aderência de áreas de concentração, linhas de pesquisa e disciplinas; (b) formação e composição do corpo docente, bem como sua aderência, seu regime de trabalho e a liderança e o reconhecimento acadêmicos; (c) planejamento estratégico e autoavaliação. Diversos conteúdos desse quesito encontram-se mais claros e objetivos, além do que se deixou explícito que "o não atendimento dos requisitos mínimos de entrada no sistema, previstos no documento orientador de APCN, implicará a atribuição de conceito Fraco ao Quesito 1, independentemente da pontuação nos demais subitens" (observação 3 ao Quesito 1).

O quesito 2 (Formação) combinou elementos de avaliação quantitativa (número de produções) e qualitativa (apreciação de alguns produtos representativos, indicados pelos programas) e introduziu, também de modo inédito, o sistema de clusters. As avaliações dar-se-ão, de modo separado, (a) para programas apenas com Mestrado e para os que possuem Mestrado e Doutorado; (b) e considerando a dimensão dos programas, o que os distingue pelo tamanho do corpo docente. Com essa segregação avaliativa, tenta-se eliminar uma distorção comum em processos anteriores, por meio da qual grandes programas eram comparados com programas pequenos.

$\mathrm{O}$ quesito 3 (Impacto na sociedade) ganhou um peso diferenciado e distinguiu os programas quanto ao nível de impacto - regional, nacional ou internacional. Com isso deu-se também uma interessante segregação voluntária entre os programas. Cada um apresenta-se ao sistema de avaliação conforme seu planejamento e sua vocação. O egresso é um dos núcleos deste quesito. Interessa saber quem é formado, para que é formado e qual o destino das pessoas que o programa oferece à sociedade e à comunidade acadêmica.

Outros elementos de avaliação, especialmente o impacto social e o impacto acadêmico, ganharam significativo protagonismo na Ficha de Avaliação, o que terá um efeito não-imediato nas políticas regulatórias, na organização normativa interna dos programas, nos processos de credenciamento e recredenciamento de docentes e na admissão, aprovação ou reprovação de discentes. O caráter nãoimediato da eficácia desse novo modelo é justificado pela demora natural de qualquer processo regulatório top-down em alcançar os níveis inferiores do sistema. ${ }^{27}$ Não

27 O modelo de regulação no âmbito da CAPES possui muitas características do modelo bottom-up, como, por exemplo, a participação da comunidade acadêmica nas instâncias de elaboração das diretrizes e dos documentos, por meio da designação de seus representantes para coordenações de Área, colégios de grandes Áreas, CTC-ES e o Conselho Superior da CAPES. Mas esse caráter é mais aparente do que real, na medida em que não se consegue mensurar o impacto da burocracia interna da CAPES na formulação e na execução de sua política regulatória, além de outros fenômenos ou processos há muito tempo conhecidos na Teoria da Regulação, ao exemplo da teoria da captura, seja em sua modalidade materialista, seja na modalidade não materialista. 
há uma absorção rápida das mudanças regulatórias, o que é acentuado por um histórico problema de assimetria informacional na CAPES, em geral, e no Direito, em particular, embora, quanto a este último, no período 2018-2022, os esforços para sua eliminação hajam sido muito eficientes. ${ }^{28}$

8. O futuro hoje: o fordismo está morto, viva o impacto?

A chegada da era pós-fordista e sua substituição por um modelo orientado ao impacto lembra uma frase de tom sarcástico que se ouve na Alemanha a respeito dos primos austríacos: "Se o mundo vai acabar, viaje até a Áustria, porque lá tudo acontece com 100 anos de atraso". Quando a pós-graduação começa a aceitar a superação do modelo fordista, ganha corpo a contestação ao uso do fator de impacto para aferição da qualidade da pós-graduação ou como critério para a admissão ou a progressão horizontal ou vertical de docentes universitários. A revista Nature, em matéria recente, informa que a Universidade de Utrecht, no Reino dos Países Baixos, a partir de 2022, não utilizará mais o fator de impacto como critério admissional ou de progressão para docentes. A justificativa é que o uso do fator de impacto gerou uma série de distorções, em especial a valorização pura e simples da produção em detrimento da qualidade real da pesquisa científica. $^{29}$

Nesse sentido, há alguns desafios para o "futuro atual", com o perdão pela licença poética, da pós-graduação em Direito:

(1) A definição do que seja o real fator de impacto: Ainda não se conseguiu encontrar um método que substitua o fator de impacto como índice objetivo de qualidade da produção científica. Mas ele não deverá sobreviver por muito mais tempo sem uma criteriosa revisão. Se isso não ocorrer, o processo de contestação ao modelo será tão forte e (provavelmente) tão eficaz quanto o surgido contra ofordismo. Citações cruzadas, fraudes nas citações induzidas e publicações fake com altos escores nos grandes indicadores internacionais (a prova mais eloquente de sua falibilidade) são apenas alguns exemplos da fragilidade de um modelo que não possui defesas (atuais) contra o uso massivo de robôs e de outras ferramentas que acentuam antigos mecanismos de burla do sistema.

\footnotetext{
28 A assimetria informacional não é um problema único ou isolado. Há questões até mais graves como a ausência de análise de impacto regulatório e a aplicação imediata e retroativa de novas diretrizes de avaliação para os quadriênios em curso.

29 WOOLSTON, Chris. Impact factor abandoned by Dutch university in hiring and promotion decisions. Nature, 25.6.2021. Disponível em: https://www.nature.com/articles/d41586-021-01759-5. Acesso em: 23 jul. 2021.
} 
(2) A perda de valor dos títulos acadêmicos: O famoso discurso de Steve Jobs como paraninfo de 2005 na Universidade de Stanford, Califórnia, é emblemático sobre a crise simbólica e representativa do ensino superior como instrumento necessário para a mudança de condição social dos indivíduos. ${ }^{30} \mathrm{O}$ fundador da multinacional Apple e responsável pela grande transformação tecnológica do início do século XXI, disse que uma das mais importantes decisões de sua vida foi deixar a universidade e buscar no mundo exterior o aprendizado que o conduziu à condição de bilionário. Os custos com anuidades eram um desperdício para o filho da classe trabalhadora, que acreditava na mediação do ensino superior como elemento essencial para sua ascensão. Há quem compare os títulos universitários, neles incluídos os de pós-graduação, como as então caríssimas licenças dos taxistas: tornaram-se inúteis em um mundo de competição brutal com os motoristas de aplicativos. Esse será um desafio crescente para a pós-graduação, particularmente no Direito.

(3) A pós-graduação à distância: A pandemia da Covid-19 acelerou em 2 anos o que ocorreria em 1 ou 2 décadas, a saber, a universalização das plataformas digitais como mecanismos de ensino-aprendizagem. Com isso, os imensos espaços das sedes de faculdades, as salas-de-aula, os ambientes de convivência presencial foram postos em xeque quanto a sua real utilidade. No quadriênio sob minha coordenação, a Área do Direito não aprovou qualquer modalidade de mestrado ou doutorado à distância. Essa questão, todavia, será reapresentada em muito brevemente. E, conectando-se com o problema anterior, o ensino à distância na pós-graduação também acentuará a dúvida sobre o real valor dos diplomas, na medida em que a base de potenciais pós-graduandos será expandida em escala exponencial com o uso das plataformas.

Abstraindo essas três questões que correspondem ao (contraditório) conceito de "futuro atual" da pós-graduação (em Direito), é importante ainda salientar algumas tendências na pós-graduação em Direito, que merecerão um lugar de destaque nas políticas regulatórias da Área no próximo quadriênio:

(1) O papel dos periódicos jurídicos. Diferentemente de outras Áreas, o Direito assistiu a um aumento significativo do número de periódicos jurídicos. A criação do software livre Open Journal Systems - OJS pelo Public Knowledge Project - PKP, um consórcio liderado pela Universidade da Columbia Britânica (Canadá), foi responsável por essa expansão, dadas sua facilidade de uso, interoperabilidade e gratuidade. Com isso, rompeu-se com uma tradição (internacional) de periódicos setoriais relevantes para áreas específicas. Essa difusão exagerada de periódicos, infelizmente induzida por uma

30 Discurso disponível em texto e vídeo aqui: https://news.stanford.edu/2005/06/14/jobs-061505/. Acesso em: 25 jul. 2021. 
política regulatória não baseada em análise de impacto, gerou diversas externalidades negativas. A falsa ideia de que cada programa de pós-graduação em Direito deveria ter seu próprio periódico e que isso seria positivo para sua avaliação está na raiz desse problema. Isso é agravado pela associação desse fenômeno com o modelo fordista e sua penetração no sistema oficial de avaliação de revistas científicas pela CAPES, conhecido como Qualis Periódicos. É provável que o efeito gerado pela redução do peso do produtivismo na avaliação termine por gerar a diminuição do número de periódicos e a concentração em torno de alguns que sejam referências em setores específicos do conhecimento jurídico.

(2) Mobilidade e internacionalização. Esses dois tópicos são relativamente antigos nas discussões sobre a política regulatória em pós-graduação. A mobilidade acadêmica, especialmente nos anos 2000-2010, ganhou enorme impulso no Brasil graças a incentivos gerados pelas agências nacionais e internacionais de fomento. A ausência de análise de impacto regulatório e de um maior controle dos resultados desses programas colocaram em dúvida a eficácia dessa mobilidade acadêmica. Isso fica evidente por meio de alguns elementos: a) número elevado de pesquisadores no estrangeiro que não retornaram ao país após o prazo de afastamento; b) baixa correlação entre os incentivos e as bolsas para determinados países e as necessidades internas no âmbito da pesquisa, da ciência e tecnologia, e da inovação; c) reflexo pequeno na qualidade da produção científica nacional em razão desses investimentos com mobilidade.

Quanto à internacionalização, especialmente no Direito, será necessária uma política de indução às atividades em rede com outras instituições estrangeiras, bem como o direcionamento da produção intelectual para periódicos de qualidade no exterior ou para revistas nacionais, mas com uso do inglês. Esse processo terá de ser iniciado após uma ampla discussão interna na pós-graduação. Sua não ocorrência no período 2018-202 foi resultado da necessidade prévia de administração da passagem do modelo fordista para o novo modelo de impacto. Até que isso ocorresse, não seria viável uma transição em paralelo.

\section{Conclusões}

Neste artigo apresentou-se um cenário da transição da pós-graduação em Direito em três momentos históricos: do modelo renascentista ao modelo fordista e, deste último, para o modelo orientado ao impacto. Foram diferentes modelos em épocas diversas, cada um deles com suas características e seus aspectos negativos e positivos. Se o modelo renascentista propiciou uma era de maior liberdade regulatória, com algumas produções de enorme qualidade e permanência, o reverso da medalha foi a entrada ou a continuidade no sistema de um número significativo de docentes que não compreendiam a representação e a função social da pós-graduação. 
O modelo fordista permitiu a introdução de regras igualitárias nos processos de admissão, progressão e credenciamento de docentes, conferindo maior profissionalismo à atividade docente e uma transversalidade dos elementos comuns da pós-graduação aos diferentes "colégios" de conhecimento (Humanidades, Ciências da Vida e Ciências Exatas). A outra face desse segundo modelo é conhecida e muito criticada: produtivismo estéril, avaliação de docentes que priorizava a contagem de pontos e não a qualidade ou impacto de suas pesquisas, equiparação nociva entre programas formalmente adequados aos parâmetros de qualidade e aqueles substancialmente relevantes para a geração de conhecimento, dentre outras mazelas já descritas neste texto e em literatura bastante disseminada. O novo modelo, que já começa a ser contestado, trouxe uma orientação do sistema ao impacto, seja ele social (de difícil mensuração) ou acadêmico, este último lastrado nos fatores de impacto. As discussões sobre a bondade desse novo modelo passam pela qualificação do que seja o impacto e pela utilidade dos sistemas atuais para sua aferição.

A Área do Direito, no período de 2018-2022, conseguiu enormes avanços, traduzidos em seus documentos e suas fichas, além da regência do processo de abandono do modelo fordista e da eliminação de diversas disfunções do sistema, a maior parte delas conhecida e criticada na literatura especializada. O saldo é, portanto, positivo. Caberá aos novos dirigentes da Área dar sequência a esse programa e não permitir que haja nele qualquer retrocesso. E, fundamentalmente, resistir à colonização da Área do Direito por outras do chamado núcleo duro das Ciências. É preciso integrar-se, mas não é admissível perder a especificidade e a diversidade entre as Áreas. Lembrem-se os que vierem do célebre dístico latino de Horácio, no livro primeiro de suas Epístolas, apropriado por Kant: Sapere aude. Atrevam-se a conhecer. A conhecer o sistema e seu passado. 